\title{
Smoking Cessation and Desire to Stop Smoking in Nine Countries of the Former Soviet Union
}

\author{
Katharine Footman $\mathrm{MSc}^{1}$, Bayard Roberts $\mathrm{PhD}^{1}$, Andrew Stickley $\mathrm{PhD}^{1-3}$, Kseniya Kizilova $\mathrm{MA}^{4}$, \\ David Rotman $\mathrm{PhD}^{5}$, Martin McKee $\mathrm{MD}^{1}$ \\ ${ }^{1}$ European Centre on Health of Societies in Transition, London School of Hygiene and Tropical Medicine, London, UK; \\ ${ }^{2}$ Stockholm Centre on Health of Societies in Transition, Södertörn University, Stockholm, Sweden; ${ }^{3}$ Department of Human \\ Ecology, Graduate School of Medicine, University of Tokyo, Japan; ${ }^{4}$ East-Ukrainian Foundation for Social Research, Kharkiv, \\ Ukraine; ${ }^{5}$ Center for Sociological and Political Research, Belarusian State University, Minsk, Belarus
}

Corresponding Author: Katharine Footman, MSc, European Centre on Health of Societies in Transition, London School of Hygiene and Tropical Medicine, London, UK. Telephone: +44 2079272 594; Fax:+44 2079272701 E-mail: katharine.footman@ @shtm.ac.uk

Received November 12, 2012; accepted February 15, 2013

\begin{abstract}
Introduction: Smoking rates and corresponding levels of premature mortality from smoking-related diseases in the former Soviet Union (fSU) are among the highest in the world. To reduce this health burden, greater focus on smoking cessation is needed, but little is currently known about rates and characteristics of cessation in the fSU.

Methods: Nationally representative household survey data from a cross-sectional study of 18,000 respondents in Armenia, Azerbaijan, Belarus, Georgia, Kazakhstan, Kyrgyzstan, Moldova, Russia, and Ukraine were analyzed to describe patterns of desire and action taken to stop smoking, quit ratios (former ever-smokers as a percent of ever-smokers, without a specified recall period), and help used to stop smoking. Multivariate logistic regression was used to analyze characteristics associated with smoking cessation and desire to stop smoking.

Results: Quit ratios varied from $10.5 \%$ in Azerbaijan to $37.6 \%$ in Belarus. About $67.2 \%$ of respondents expressed a desire to quit, and $64.9 \%$ had taken action and tried to stop. The use of help to quit was extremely low (12.6\%). Characteristics associated with cessation included being female, over 60, with higher education, poorer health, lower alcohol dependency, higher knowledge of tobacco's health effects, and support for tobacco control. Characteristics associated with desire to stop smoking among current smokers included younger age, poorer health, greater knowledge of tobacco's health effects, and support for tobacco control.
\end{abstract}

Conclusions: Quit ratios are low in the fSU but there is widespread desire to stop smoking. Stronger tobacco control and cessation support are urgently required to reduce smoking prevalence and associated premature mortality.

\section{INTRODUCTION}

Smoking rates in countries of the former Soviet Union (fSU) are among the highest in the world, reflected in very high premature mortality from smoking-related causes (Andreev, Nolte, Shkolnikov, Varavikova, \& McKee, 2003; Ezzati \& Lopez, 2003; World Health Organization, 2011). Although male smoking was widespread in the Soviet era (Cockerham, Snead, \& Sewaal, 2002), the tobacco market was transformed following the Soviet Union's collapse by the entry of transnational companies (Gilmore \& McKee, 2004b). Female smoking increased substantially (from $7 \%$ to $15 \%$ between 1992 and 2003 in Russia), while the age of smoking initiation fell, as both women and young people were specifically targeted by the tobacco industry (Gilmore \& McKee, 2004a). Smoking prevalence has now stabilized but remains extremely high among men (49\% daily smoking; Roberts, Gilmore, et al., 2012).

There is an urgent need to reduce smoking rates in the fSU, which will require an emphasis on both smoking cessation and initiation. Apart from Russia and Ukraine, however (Andreeva \& Krasovsky, 2011; Giovino et al., 2012; Schnoll, Engstrom, Subramanian, Demidov, \& Wielt, 2006; Schnoll, Subramanian, Martinez, \& Engstrom, 2011; Squier, Hesli, Lowe, Ponamorenko, \& Medvedovskaya, 2008), little is known of smoking cessation rates and desire to stop smoking in the fSU. The aim of this study was twofold: (a) to determine the extent of smoking cessation, and the desire, action taken, and help used to stop smoking in nine fSU countries; (b) to examine which factors are associated with the desire to stop smoking and smoking cessation in these countries. 


\section{METHODS}

The data for this study were derived from household surveys in Armenia, Azerbaijan, Belarus, Georgia, Kazakhstan, Kyrgyzstan, Moldova, Russia, and Ukraine in 2010 for the Health in Times of Transition (HITT) study (www.hitt-cis.net). These surveys have been described elsewhere (Balabanova, Roberts, Richardson, Haerpfer, \& McKee, 2012), but in brief they used nationally representative cross-sectional design and multi-stage random sampling. Primary sampling units were selected from a sampling frame of a complete list of local administrative units. Households were selected using the random walk method, and one person (aged 18+) was randomly chosen for a face-to-face interview using a standardized questionnaire. The draft questionnaire was developed in English and then translated into Russian and local languages (except in Russia and Belarus where only Russian was needed), using standard forward and back translation procedures. Respondents were then given the choice of answering in Russian or a local language (except in Russia and Belarus). Individual exclusion criteria included being institutionalized, hospitalized, or homeless, being intoxicated at the time of the survey, and being in the military or in prison. Country response rates varied from $47 \%$ to $83 \%$. The research was approved by the ethics committee of the London School of Hygiene and Tropical Medicine.

Descriptive statistics determined the prevalence of daily smoking, desire to stop, and action taken to stop among daily smokers, quit ratios, and help used by former smokers when stopping. Daily smokers were those who currently smoke at least one cigarette (or one papirossi [Russian cigarette], pipe, cigar, etc.) per day. Daily smokers were asked "would you like to give up smoking" and "how many times have you tried to give up smoking" to ascertain their desire to stop smoking and action taken to stop. Former smokers were identified by asking nonsmokers whether they had ever smoked, but then stopped, or had never smoked, and there was no specific recall period. Quit ratios (former eversmokers as percent of ever-smokers) were then calculated, as used elsewhere (Giovino et al., 2012; World Health Organization, 2002). To calculate how long ago they had stopped, former smokers were asked their age when they quit. Former smokers were asked whether they had used any of the following types of help when they quit most recently: nicotine chewing gum, nicotine patches, hypnosis, acupuncture, or "other."

Determinants of smoking cessation were examined using logistic regression. Two models were developed: the first modelled the determinants of an outcome of being a former smoker among ever-smokers and the second modelled the determinants of an outcome of wanting to stop among daily smokers. Key independent variables of health, health behavior (alcohol dependency), knowledge of tobacco's health effects, and support for tobacco control measures were selected, and their association with the two outcomes was examined using multivariate analysis, adjusting for country of residence, gender, age, self-rated household economic situation, and education. The health variable was self-rated health status on a 5-point scale. Alcohol dependency was derived from the CAGE questionnaire: responses to four standard questions were scored 0 or 1 , and summed to produce a score from 0 to 4 , with a score of 2 or higher indicating alcohol dependency (Buchsbaum, Buchanan, Centor, Schnoll, \& Lawton, 1991).

Knowledge of health effects was a score aggregated from whether respondents thought smoking was a cause $(1=$ yes;
$0=$ no) of seven smoking-related diseases: cardiovascular disease, stroke, lung cancer, bronchitis, tooth decay, infertility, and impotence. This produced a score range of $0-7$, which was categorized into three groups as follows: low (0-2), medium (3-4), and high (5-7). Support for tobacco control activities was derived from respondents' support $(1=$ yes; $0=$ no $)$ for four specific measures: increased tobacco prices, larger text and pictorial warnings on cigarette packages, and smoking bans. These scores were aggregated to produce a scoring range of $0-4$, which was again categorized into three groups of low (0-1), medium (2), and high (3-4). These measures have not been formally validated, but have been used previously and described in detail (Danishevski, Gilmore, \& McKee, 2008; Roberts, Stickley, et al., 2012). The entire study sample was combined to ensure greater statistical power, and data were adjusted for the sampling design effect.

\section{RESULTS}

Of the 18,000 respondents, $56 \%$ were women and $44 \%$ men and the mean age was 43.3 years. Further details are provided elsewhere (Roberts, Gilmore, et al., 2012).

Table 1 lists descriptive statistics. Of the total study sample, 4,647 (25.9\%) were daily smokers and 1,789 (13.4\%) were former smokers. Among daily smokers, desire to quit was high in every country, ranging from $50.8 \%$ in Armenia to $82.6 \%$ in Georgia. However, action taken was generally lower; $55 \%$ of smokers in Kazakhstan had made a quit attempt compared with $79.7 \%$ in Moldova.

As a proportion of ever-smokers, $27.8 \%$ had quit in the region as a whole, and this proportion varied from $10.5 \%$ in Azerbaijan to $37.6 \%$ in Belarus (Table 1). Of former smokers, those respondents who had successfully stopped smoking, $8 \%$ had stopped in the past year and $45 \%$ had stopped smoking 5 years ago or less.

Across the region, just $12.6 \%$ of former smokers had used help to stop smoking, but there were substantial differences between countries: $19.1 \%$ of former smokers in Belarus had used help compared with $3.7 \%$ in Armenia (Table 1). Nicotine gum was the most commonly used $(0 \%$ in Georgia to $4.4 \%$ in Azerbaijan), but most respondents listed "other" (0.9\% in Armenia to $15.4 \%$ in Russia).

Table 2 presents the multivariate analysis results. Characteristics associated with being a former smoker among eversmokers included being female, older age (which may reflect selective survival), higher education, not harmful drinking, and increased knowledge of tobacco's health effects and support for tobacco control. Compared with Russia (taken as the index as the most-developed tobacco market), ever-smokers were less likely to have quit in Armenia and Azerbaijan, and more likely in Belarus, Georgia, Moldova, and Ukraine. Characteristics associated with desire to stop smoking among daily smokers included younger age, poorer health, higher knowledge of tobacco's health effects, and support for tobacco control. Compared with Russia, desire to quit was higher in Azerbaijan, Georgia, Kyrgyzstan, Moldova, and Ukraine.

\section{DISCUSSION}

To the best of our knowledge, this is the first study from the fSU to provide directly comparable data from a range of countries on smoking cessation. It reveals substantial variation in 


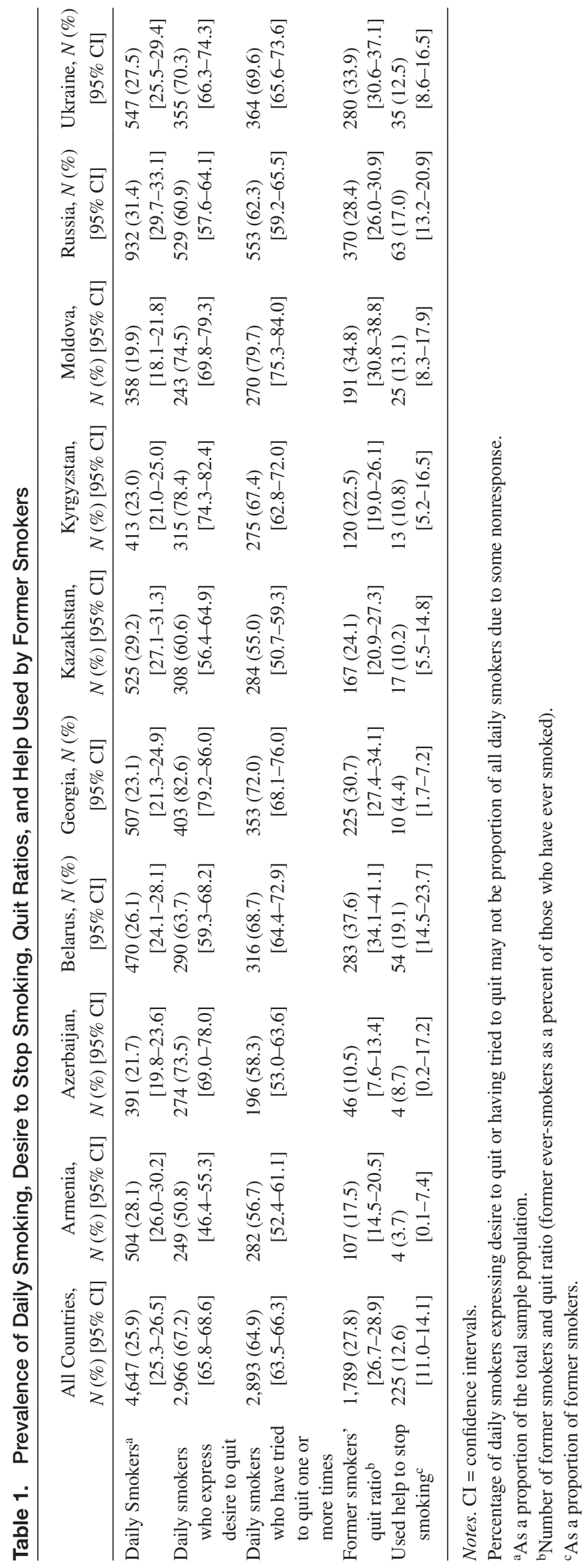


Table 2. Characteristics Associated With Being a Former Smoker and Desire to Stop Smoking

\begin{tabular}{|c|c|c|c|c|c|c|c|c|}
\hline & \multicolumn{4}{|c|}{ Former smoker ${ }^{\mathrm{a}}$} & \multicolumn{4}{|c|}{ Desire to stop smoking } \\
\hline & $N(\%)^{\mathrm{b}}$ & $O R$ & $95 \% \mathrm{CI}$ & $p$ Value & $N(\%)^{\mathrm{c}}$ & $O R$ & $95 \% \mathrm{CI}$ & $p$ Value \\
\hline Russia & $370(28.4)$ & 1.00 & & & $529(60.9)$ & 1.00 & & \\
\hline Armenia & $107(17.5)$ & 0.72 & [0.53-0.97] & .03 & $249(50.8)$ & 0.83 & {$[0.59-1.16]$} & .28 \\
\hline Azerbaijan & $46(10.5)$ & 0.30 & [0.18-0.49] & $<.01$ & $274(73.5)$ & 2.25 & {$[1.48-3.41]$} & $<.01$ \\
\hline Belarus & $283(37.6)$ & 1.75 & {$[1.40-2.18]$} & $<.01$ & $290(63.7)$ & 1.22 & {$[0.92-1.61]$} & .17 \\
\hline Georgia & 225 (30.7) & 1.36 & [1.05-1.75] & .02 & 403 (82.6) & 3.38 & {$[2.46-4.65]$} & $<.01$ \\
\hline Kazakhstan & $167(24.1)$ & 1.01 & {$[0.76-1.34]$} & .94 & $308(60.6)$ & 1.05 & {$[0.79-1.41]$} & .73 \\
\hline Kyrgyzstan & $120(22.5)$ & 0.82 & {$[0.60-1.12]$} & .20 & $315(78.4)$ & 2.26 & [1.62-3.15] & $<.01$ \\
\hline Moldova & $191(34.8)$ & 1.33 & [1.04-1.71] & .02 & $243(74.5)$ & 1.93 & {$[1.34-2.78]$} & $<.01$ \\
\hline Ukraine & $280(33.9)$ & 1.41 & [1.12-1.77] & $<.01$ & $355(70.3)$ & 1.56 & [1.16-2.09] & $<.01$ \\
\hline \multicolumn{9}{|l|}{ Gender } \\
\hline Female & $515(37.3)$ & 1.00 & & & $572(69.9)$ & 1.00 & & \\
\hline Male & $1,274(25.2)$ & 0.61 & {$[0.52-0.73]$} & $<.01$ & $2,394(66.5)$ & 0.98 & {$[0.79-1.20]$} & .82 \\
\hline \multicolumn{9}{|l|}{ Age } \\
\hline $18-29$ & $480(25.5)$ & 1.00 & & & $912(68.5)$ & 1.00 & & \\
\hline $30-39$ & $296(21.3)$ & 0.77 & {$[0.64-0.93]$} & .01 & $722(69.2)$ & 0.92 & {$[0.76-1.11]$} & .39 \\
\hline $40-49$ & $303(23.2)$ & 0.95 & {$[0.77-1.18]$} & .66 & 659 (68.6) & 0.83 & {$[0.68-1.03]$} & .09 \\
\hline $50-59$ & $279(28.9)$ & 1.22 & {$[0.97-1.54]$} & .09 & $433(66.8)$ & 0.71 & {$[0.55-0.90]$} & 0.01 \\
\hline $60+$ & $431(48.5)$ & 2.99 & [2.36-3.79] & $<.01$ & $240(55.7)$ & 0.51 & [0.38-0.67] & $<.01$ \\
\hline \multicolumn{9}{|l|}{ Education } \\
\hline Incomplete secondary & $188(27.6)$ & 1.00 & & & $306(66.4)$ & 1.00 & & \\
\hline Completed secondary & $1,105(25.8)$ & 1.06 & [0.84-1.33] & .62 & $2,009(66.6)$ & 1.00 & {$[0.78-1.28]$} & .97 \\
\hline Higher education & $491(33.5)$ & 1.43 & [1.11-1.85] & .01 & $646(69.4)$ & 1.03 & [0.77-1.39] & .83 \\
\hline \multicolumn{9}{|l|}{ Economic situation } \\
\hline Very good & $25(29.8)$ & 1.00 & & & $32(56.1)$ & 1.00 & & \\
\hline Good & $371(28.4)$ & 1.04 & [0.56-1.94] & .91 & $579(64.0)$ & 1.53 & {$[0.80-2.92]$} & .20 \\
\hline Average & $1,027(27.7)$ & 1.04 & [0.56-1.92] & .90 & $1,720(67.8)$ & 1.77 & [0.93-3.39] & .08 \\
\hline $\mathrm{Bad}$ & 285 (26.6) & 0.84 & [0.44-1.58] & .58 & $518(69.6)$ & 1.78 & {$[0.92-3.46]$} & .09 \\
\hline Very bad & $47(25.1)$ & 0.62 & [0.29-1.34] & .22 & $94(71.8)$ & 1.93 & {$[0.88-4.23]$} & .10 \\
\hline \multicolumn{9}{|l|}{ Health } \\
\hline Very good & $93(21.6)$ & 1.00 & & & $195(60.4)$ & 1.00 & & \\
\hline Good & $567(24.6)$ & 1.14 & [0.85-1.54] & .39 & $1,060(64.5)$ & 1.27 & {$[0.95-1.70]$} & .10 \\
\hline Average & $781(28.1)$ & 1.03 & {$[0.76-1.40]$} & .85 & $1,337(70.2)$ & 1.72 & [1.26-2.33] & $<.01$ \\
\hline $\mathrm{Bad}$ & $288(37.7)$ & 1.41 & [1.00-1.99] & .05 & 307 (67.6) & 1.55 & {$[1.06-2.26]$} & 0.02 \\
\hline Very bad & $51(39.2)$ & 1.49 & {$[0.83-2.67]$} & .18 & $54(72.0)$ & 1.67 & {$[0.87-3.23]$} & .13 \\
\hline \multicolumn{9}{|l|}{ Alcohol dependency } \\
\hline Cage 0 & $1,028(31.3)$ & 1.00 & & & $1,442(67.4)$ & 1.00 & & \\
\hline Cage 1 & $263(26.0)$ & 0.78 & {$[0.66-0.93]$} & .01 & $464(63.9)$ & 0.83 & [0.69-1.01] & .06 \\
\hline Cage 2 & 187 (23.7) & 0.70 & {$[0.57-0.86]$} & $<.01$ & $399(69.3)$ & 1.08 & [0.87-1.33] & .50 \\
\hline Cage 3 & $125(21.2)$ & 0.62 & {$[0.49-0.79]$} & $<.01$ & $320(71.8)$ & 1.24 & [0.97-1.58] & .09 \\
\hline Cage 4 & $84(22.0)$ & 0.72 & {$[0.53-0.99]$} & .04 & $191(69.0)$ & 1.02 & {$[0.74-1.41]$} & .90 \\
\hline \multicolumn{9}{|l|}{ Tobacco knowledge } \\
\hline Low & $528(21.8)$ & 1.00 & & & $1,128(63.0)$ & 1.00 & & \\
\hline Average & $780(29.2)$ & 1.34 & [1.15-1.56] & $<.01$ & $1,211(67.4)$ & 1.32 & [1.13-1.55] & $<.01$ \\
\hline High & $481(35.9)$ & 1.56 & [1.29-1.87] & $<.01$ & $627(75.7)$ & 1.93 & {$[1.53-2.44]$} & $<.01$ \\
\hline \multicolumn{9}{|l|}{ Tobacco control support } \\
\hline Low & $886(20.6)$ & 1.00 & & & $2,093(64.2)$ & 1.00 & & \\
\hline Average & $392(37.9)$ & 2.47 & [2.09-2.93] & $<.01$ & $471(76.1)$ & 1.69 & {$[1.36-2.10]$} & $<.01$ \\
\hline High & $263(51.5)$ & 4.42 & [3.52-5.55] & $<.01$ & $197(82.1)$ & 2.24 & [1.53-3.29] & $<.01$ \\
\hline
\end{tabular}

Notes. $\mathrm{OR}=$ odds ratio; $\mathrm{CI}=$ confidence interval. Results in bold are statistically significant at $p<.05$.

${ }^{\text {aF }}$ ormer smokers are those who have ever-smoked and then stopped.

${ }^{\mathrm{b}}$ As proportion of ever-smokers.

${ }^{\mathrm{c}}$ As proportion of daily smokers.

quit ratios and use of cessation support between countries of the fSU. The quit ratio and use of help was highest in Belarus, whereas Armenia and Azerbaijan had very low quit ratios and help was rarely used. Although not directly comparable with daily smoker quit ratios, the fSU regional average quit ratio of $27.8 \%$ is considerably lower than that of many countries in Western Europe, North and South America, and parts of Africa (Giovino et al., 2012; World Health Organization, 2002). Although desire to stop smoking across the region is higher than in other countries (World Health Organization, 2011), the 
proportion of respondents that had attempted to quit was lower than elsewhere (World Health Organization, 2012).

The findings suggest there is inadequate encouragement for smoking cessation in much of the fSU. Although the role of smoking cessation support is contested (Chapman \& Wakefield, 2012), it is notable that there were higher quit ratios in those countries where more help was used. Additionally, in Belarus, where nicotine replacement therapy and at least one cessation service are included in the health benefit package (World Health Organization, 2011), the quit ratio and use of cessation services were highest, and in Azerbaijan, where smoking cessation services are not available (World Health Organization, 2011), the quit ratio was lowest, and use of services was very low. The pattern does not always hold; in Kazakhstan, cessation services are available and funded to the same extent as in Belarus, but its quit ratio and use of services were one of the lowest. The remainder of the countries in our study fall somewhere in between, with cessation services available, but not cost covered. Nevertheless, cessation services can double smokers' chances of stopping permanently (Frieden \& Bloomberg, 2007), at least among those who avail of them, and research from the region reveals a lack of training for, and involvement of, physicians in smoking cessation, and misinformed beliefs about smoking among physicians (Schnoll et al., 2006; Squier et al., 2008). More information is needed on the quality, affordability, and accessibility of cessation services in the region to fully understand why their utilization is so low.

Although alcohol dependency is not associated with a desire to quit, it is negatively associated with smoking cessation, supporting previous research on the clustering of risk factors (Jackson, Henderson, Frank, \& Haw, 2012) and the suggestion that combined programmes aimed at reducing nicotine and alcohol dependency together may prove more effective (Roberts et al., 2013). Given the association between knowledge of tobacco's health effects and smoking cessation, the low levels of knowledge in the region (Roberts, Stickley et al., 2012) also need to be addressed through stronger and more graphic health warnings on packets (Wade, Merrill, \& Lindsay, 2011) and public awareness campaigns. Tobacco control policies such as tobacco pricing, advertising, and restricting smoking in public places must also be strengthened (Mir, Roberts, Richardson, Chow, \& McKee, 2012; Roberts, Stickley et al., 2012; World Health Organization, 2012).

The study has a number of limitations. Smoking status was not validated by biomarkers, but evidence suggests that selfreported smoking can be accurate, especially when data are collected in respondents' homes (Patrick et al., 1994). We used "former ever-smoker" rather than the more commonly used "former daily smoker." However, compared with the Global Adult Tobacco Survey in Russia and Ukraine (GATS, 2009, 2010), the quit ratios of former daily and occasional smokers combined (26.1\% in Russia and $34.4 \%$ in Ukraine) are similar to our estimates of former ever-smokers, suggesting good external validity. Additionally, we do not know whether our defined former smokers were regular smokers, or whether their experimentation with smoking was just short-lived. Because there was no specific recall period for being a former smoker, this definition may also have been subject to recall bias. A further limitation concerns the question that addressed help received by former smokers when quitting because it did not cover types of cessation support such as counseling from a health professional. Given the small number of female smokers, we did not analyze the two sexes separately, but we did undertake separate regression analyses for men only; there were no significant differences between the analyses with men alone and the sample as a whole. Additionally, there are many factors, such as peer and household smoking, which may be predictors of quitting, but were not measured and therefore left out of the regression analysis. Lastly, the cross-sectional design means this study cannot explain the temporal relationship between these factors and smoking cessation.

This study shows that smoking cessation ratios are low in much of the fSU, but there is considerable desire to stop smoking. The introduction of stronger tobacco control measures and provision of greater support for smoking cessation are now urgently needed to reduce the severe health burden caused by smoking in these countries. Further research is also required to better understand accessibility and affordability of cessation services, as well as the factors influencing quit ratios in this region.

\section{FUNDING}

This work was supported by the European Union's 7th Framework Program, project HEALTH-F2-2009-223344. The European Commission cannot accept any responsibility for any information provided or views expressed.

\section{DECLARATION OF INTERESTS}

None declared.

\section{ACKNOWLEDGMENTS}

We are grateful to all members of the HITT study who participated in the coordination and organization of data collection for this article.

\section{REFERENCES}

Andreev, E., Nolte, E., Shkolnikov, V., Varavikova, E., \& McKee, M. (2003). The evolving pattern of avoidable mortality in Russia. International Journal of Epidemiology, 32, 437-446. doi:10.1093/ije/dyg085

Andreeva, T., \& Krasovsky, K. (2011). Recall of tobacco pack health warnings by the population in Ukraine and its association with the perceived tobacco health hazard. International Journal of Public Health, 56, 253-262. doi:10.1007/ s00038-010-0226-4

Balabanova, D., Roberts, B., Richardson, E., Haerpfer, C., \& McKee, M. (2012). Health care reform in the former Soviet Union: Beyond the transition. Health Services Research, 47, 840-864. doi:10.1111/j.1475-6773.2011.01323.x

Buchsbaum, D., Buchanan, R., Centor, R., Schnoll, S., \& Lawton, M. (1991). Screening for alcohol abuse using CAGE scores and likelihood ratios. Annals of Internal Medicine, 115, 774-777. Retrieved from http://annals.org/ article.aspx? articleid $=705141$

Chapman, S., \& Wakefield, M. (2012). Smoking cessation strategies. British Medical Journal, 344. doi:10.1136/bmj.e1732

Cockerham, W., Snead, M., \& Sewaal, D. (2002). Health lifestyles in Russia and the socialist heritage. Journal of Health and Social Behaviour, 43, 42-55. doi:10.2307/3090244 


\section{Smoking cessation and desire to stop smoking}

Danishevski, K., Gilmore, A., \& McKee, M. (2008). Public attitudes towards smoking and tobacco control policy in Russia. Tobacco Control, 17, 276-283.

Ezzati, M., \& Lopez, A. (2003). Measuring the accumulated hazards of smoking: Global and regional estimates for 2000. Tobacco Control, 12, 79-85. doi:10.1136/tc.12.1.79

Frieden, T., \& Bloomberg, M. (2007). How to prevent 100 million deaths from tobacco. Lancet, 369, 1758-1761. doi:10.1016/S0140-6736(07)60782-X

Gilmore, A., \& McKee, M. (2004a). Moving East: How the transnational tobacco industry gained entry to the emerging markets of the former Soviet Union-part II: An overview of priorities and tactics used to establish a manufacturing presence. Tobacco Control, 13, 151-160. doi:10.1136/ tc. 2003.005207

Gilmore, A., \& McKee, M. (2004b). Tobacco and transition: An overview of industry investments, impact and influence in the former Soviet Union. Tobacco Control, 13, 136-142. doi:10.1136/tc.2002.002667

Giovino, G., Mirza, S., Samet, J., Gupta, P., Jarvis, M., Bhala, N., ... Group, G. C. (2012). Tobacco use in 3 billion individuals from 16 countries: An analysis of nationally representative cross-sectional household surveys. Lancet, 380, 668-679. doi:10.1016/S0140-6736(12)61085-X

Global Adult Tobacco Survey in Russia and Ukraine [GATS]. (2009). Global Adult Tobacco Survey: Russian Federation Country Report. Author.

Global Adult Tobacco Survey in Russia and Ukraine [GATS]. (2010). Global Adult Tobacco Survey: Ukraine Country Report. Author.

Jackson, C., Henderson, M., Frank, J., \& Haw, S. (2012). An overview of prevention of multiple risk behaviour in adolescence and young adulthood. Journal of Public Health (Oxf), 34(Suppl. 1), 31-40. doi:10.1093/pubmed/fdr113

Mir, H., Roberts, B., Richardson, E., Chow, C., \& McKee, M. (2012). Analysing compliance of cigarette packaging with the FCTC and national legislation in eight former Soviet Union countries. Tobacco Control. doi:10.1136/ tobaccocontrol-2012-050567

Patrick, D., Cheadle, A., Thompson, D., Diehr, P., Koepsell, T., \& Kinne, S. (1994). The validity of self-reported smoking:
A review and meta-analysis. American Journal of Public Health, 84, 1086-1093. doi:10.2105/AJPH.84.7.1086

Roberts, B., Gilmore, A., Stickley, A., Kizilova, K., Prohoda, V., Rotman, D., . . . McKee, M. (2013). Prevalence and psychosocial determinants of nicotine dependence in nine countries of the former Soviet Union. Nicotine \& Tobacco Research, 15(1), 271-276. doi:10.1093/ntr/nts100

Roberts, B., Gilmore, A., Stickley, A., Rotman, D., Prohoda, V., Haerpfer, C., \& McKee, M. (2012). Changes in smoking prevalence in 8 countries of the former Soviet Union between 2001 and 2010. American Journal of Public Health, 102, 1320-1328. doi:10.2105/AJPH.2011.300547

Roberts, B., Stickley, A., Gilmore, A., Danishevski, K., Kizilova, K., Bryden, A., ... McKee, M. (2012). Knowledge of the health impacts of smoking and public attitudes towards tobacco control in the former Soviet Union. Tobacco Control. doi:10.1136/tobaccocontrol-2011-050249

Schnoll, R., Engstrom, P., Subramanian, S., Demidov, L., \& Wielt, D. (2006). Smoking cessation counselling by Russian oncologists: Opportunities for intervention in the Russian Federation. International Journal of Behavioural Medicine, 13, 8-15. doi:10.1207/s15327558ijbm1301_2

Schnoll, R., Subramanian, S., Martinez, E., \& Engstrom, P. (2011). Correlates of continued tobacco use and intention to quit smoking among Russian cancer patients. International Journal of Behavioural Medicine, 18, 325-332. doi:10.1007/ s12529-010-9131-8

Squier, C., Hesli, V., Lowe, J., Ponamorenko, V., \& Medvedovskaya, N. (2008). Tobacco use, cessation advice to patients and attitudes to tobacco control among physicians in Ukraine. European Journal of Cancer Prevention, 15, 458-463. doi:10.1097/00008469-200610000-00012

Wade, B., Merrill, R., \& Lindsay, G. (2011). Cigarette pack warning labels in Russia: How graphic should they be? European Journal of Public Health, 21, 366-372. doi:10.1093/eurpub/ ckq098

World Health Organization. (2002). The tobacco atlas. Geneva.

World Health Organization. (2011). WHO report on the global tobacco epidemic, 2011: warning about the dangers of tobacco. Geneva.

World Health Organization. (2012). The tobacco atlas. Geneva. 